\title{
Research on Control of Rib Spalling Disaster in the Three-Soft Coal Seam
}

\author{
Feng Cui $\left.{ }^{1}\right)^{1,2,3,4}$ Tinghui Zhang, ${ }^{1,2}$ and Xiaoqiang Cheng ${ }^{1,2}$ \\ ${ }^{1}$ Energy School, Xi'an University of Science and Technology, Xi'an 710054, China \\ ${ }^{2}$ Key Laboratory of Western Mines and Hazard Prevention of China Ministry of Education, Xi'an 710054, China \\ ${ }^{3}$ Key Laboratory of Coal Resources Exploration and Comprehensive Utilization, Ministry of Natural Resources, \\ Shaanxi Coal Geology Group Co, Ltd., Xi'an 710021, China \\ ${ }^{4}$ Shaanxi Coal Industry and Chemical Technology Research Institute Co., Ltd., Xi'an 710010, China
}

Correspondence should be addressed to Feng Cui; fengc@xust.edu.cn

Received 13 April 2021; Accepted 1 June 2021; Published 16 June 2021

Academic Editor: Xue-qiu He

Copyright (c) 2021 Feng Cui et al. This is an open access article distributed under the Creative Commons Attribution License, which permits unrestricted use, distribution, and reproduction in any medium, provided the original work is properly cited.

Rib spalling disaster at the coal mining faces severely restricted the safe and efficient output of coal resources. In order to solve this problem, based on the analysis of the current status of rib spalling in the three-soft coal seam 1508 Working Face of Heyang Coal Mine, a mechanical model of sliding-type rib spalling was established and the main influencing factors that affect rib spalling are given. The mechanism of grouting technology to prevent and control rib spalling has been theoretically analyzed. A similarity simulation experiment is used to analyze the change law of roof stress under the condition of three-soft coal seam mining. The optimal grouting pressure is determined by a numerical simulation experiment. And, silicate-modified polymer grouting reinforcement materials (SMPGMs) are used in field experiments. After twice grouting operations in the 1508 Working Face, the coal wall was changed from the original soft and extremely easy rib spalling to a straight coal wall and the amount of rib spalling has been reduced by $57.45 \%$ and 48.43 , respectively. And, the mining height has increased by $0.16 \mathrm{~m}$ and $0.23 \mathrm{~m}$, respectively. The experimental results show that the rib spalling disaster of the three-soft coal seam has been effectively controlled.

\section{Introduction}

Three-soft coal seam refers to the soft roof, soft coal seam, and soft floor. Due to factors such as soft coal quality and low firmness coefficient, rib spalling often occurs in the threesoft coal seam face during the mining process. On the one hand, it affects the advancing speed of the working face. On the other hand, it is more likely to cause serious accidents such as roof fall accidents [1-3]. Therefore, it is of great significance to research on control of rib spalling disaster in the three-soft coal seam.

Existing studies show that there are various forms of rib spalling. In nearly horizontal and gently inclined coal seams, the roof pressure, the physical and mechanical properties of the coal are the main influencing factors of rib spalling. Rip spalling form of soft coal is mainly shearsliding failure $[4,5]$. Fang et al. [6] established a mechanical model of the rib spalling in soft coal fully mechanized caving face and proposed a control plan for using wood bolts in the severe areas of the rib spalling. Pang and Wang [7] established the tensile-sliding mechanical model of rib spalling of the hard and thick coal seam and obtained the relationship between the fracture depth and width of the coal wall, the strength of coal, and the mining height, and proposed the concept of "Critical Protection Force." Yang and Kong [8] studied the deformation and strength characteristics of brown rope coal samples with different diameters and proposed a flexible reinforcement technology to prevent and control rib spalling and a combination of wood bolting at the upper end of the coal wall and water injection in the coal seam of the three-soft unstable face, and comprehensive measures to strengthen the management and control of the supportsurrounding rock relationship $[9,10]$. Zhou [11] obtained the change rule of the mechanical properties under the loose coal and verified the good technical results of the coal 
wall shallow hole water injection to prevent rib spalling through the field industrial test. The bolt-grouting support theory was researched on the seepage diffusion mechanism of the bolt-grouting liquid, and the bolt-grouting support effect of the roadway was improved $[12,13]$. The mechanism of rib spalling and disaster-causing mechanism of soft steeply dipping coal fully mechanized caving face were researched $[14,15]$. Yin [16] established a cusp catastrophe model and an arc sliding instability model for a fully mechanized caving face with large mining height and proposed a "Solid-liquid Synchronization" fault detection method to control rib spalling with the core of reducing the failure ratio of the support. The compression rod mechanics model of the large mining height rib spalling in the three-soft coal seam was established, the influence of different factors was analyzed, and advanced grouting to strengthen the coal wall with large mining height was proposed [17-19]. By studying the failure mechanism of the key strata of the overburden, a method to determine the grouting drilling angle was proposed, and the complex engineering practice on-site verified the scientific nature of the theory [20-22].

The above-mentioned scholars have done a lot of research on the mechanism of rib spalling and proposed different control measures, but they have not conducted indepth discussions on on-site grouting engineering practices. In the past ten years, grouting reinforcement materials have achieved considerable development and have been widely used in the coal minefield. Kang and Feng [23] summarized the common materials for downhole grouting at present: cement-based, chemical, and cement and chemical composite grouting materials, and pointed out that chemical grouting materials have the characteristics such as fast curing, high strength, and good permeability, which can timely deal with coal accidents such as rib spalling and roof fall quickly and effectively. The polymer grouting reinforcement material for mines was a rapidly developing new application technology in the coal minefield, which can timely and efficiently deal with geological disasters encountered in underground mining and production [24]. However, serious safety problems appeared in the actual application process, such as spontaneous combustion of the material itself and poor reinforcement effect. Therefore, the in-depth research and promotion of polymer grouting materials are also continuing [25].

In this paper, the three-soft coal seam face was taken as the engineering background and based on analyzing the rib spalling form of Heyang Coal Mine 1508 Working Face, rib spalling and grouting reinforcement mechanism were explored. A similar simulation experiment was used to study the characteristics of roof stress evolution under three-soft coal seam mining conditions. A numerical simulation experiment was used to study the change law of the grouting borehole stress field under different grouting pressures. The research results to the site were applied, and the effect of grouting reinforcement was verified through different monitoring methods. This research has a good reference significance for another three-soft coal seam antirib spalling disaster prevention and control work.

\section{Engineering Background}

2.1. Mining Status of 1508 Working Face. The 1508 Working Face is located in the middle of the first mining area of the Heyang Coal Mine, and the coal seam is a three-soft coal seam. The west is the 1506 Working Face to be excavated, and the east is the 1509 Working Face to be excavated. The average inclination angle of the coal seam is $5^{\circ}$; the inclined length of the working face is $150 \mathrm{~m}$, and the strike length is $1721 \mathrm{~m}$; the average coal thickness is $4.5 \mathrm{~m}$, and the design mining height is $3.8 \mathrm{~m}$. The roof management adopts ZY4200/18/38 hydraulic support to support the roof, comprehensive mechanized mining, and the roof in the old goaf area adopts all collapse treatment. The working face layout is shown in Figure 1(a). At present, the most serious area of rib spalling in 1508 Working Face is located at the 25\# 35\# support, as shown in Figure 1(b). Rib spalling was accompanied by a large number of falling roof rocks, which made it difficult to guarantee the safety of face production personnel. The falling of roof rocks increases the difficulty of advancing the working face, leaving the exposed coal wall in a state of high stress for a long time, which will increase the amount of rib spalling and cause the vicious circle of "rib spalling-slow advancement-high stress-rib spalling." The columnar diagram of overlying strata at 1508 Working Face is shown in Figure 1(c).

2.2. Type of Rib Spalling in Three-Soft Coal Seam. The firmness coefficient of coal is between 0.3 and 0.4 . The coal is crisp and dry, with low moisture content and poor water retention. The upper coal seam is loose and broken, and the bedding is disordered; the middle layer contains gangue and falls along with the mining; the lower is relatively stable. Due to the development of cracks, joints, and beddings in the roof and coal walls, it is easy to rib spalling and roof fall, which brings great hidden dangers to the production of fully mechanized mining face. The coal about $1.5 \mathrm{~m}$ above is soft with poor integrity, which will cause direct roof and roof fall. Rib spalling at the 25\# 35\# supports is particularly serious, as shown in Figure 2(a). Based on the analysis of the actual rib spalling on-site, the rib spalling in the three-soft coal seam is sliding-type, as shown in Figure 2(b).

\section{Mechanism of Rib Spalling and Grouting Reinforcement}

3.1. Mechanism of Rib Spalling. For the three-soft coal seam, the cracks of coal wall with mining continue to develop under the coal's gravity and the overlying roof load. Under the joint action of the support and the surrounding rock, the coal wall was fully broken, resulting in the sliding-type rib spalling. The actual shear-sliding surface is a curved surface, which is simplified as a plane since the height difference between the coal wall and rib spalling is small, as shown in Figure 3. In Figure 3, $G$ is the gravity of the coal; $Q_{1}$ is the gravity of the top coal seam and the direct roof; $Q_{2}$ is the load transmitted by the main roof and the overlying rock; $Q_{3}$ is the advanced supporting pressure on the coal wall of the 


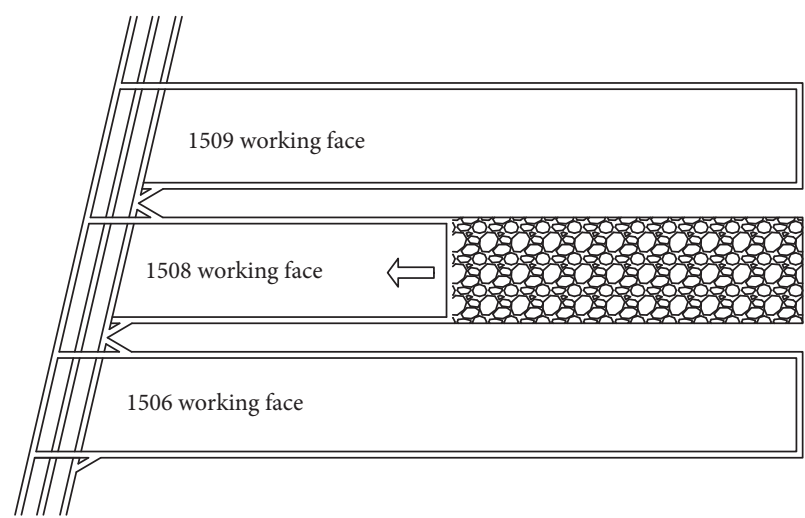

(a)

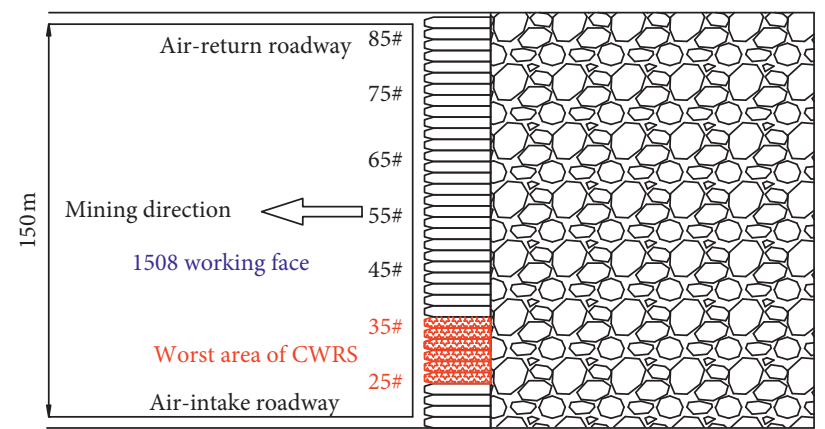

(b)

\begin{tabular}{|c|c|c|c|}
\hline No. & $\begin{array}{c}\text { Thickness } \\
/ \mathrm{m}\end{array}$ & Lithology & $\begin{array}{l}\text { Stratigraphic } \\
\text { column }\end{array}$ \\
\hline 21 & 290 & Coarse-grained sandstone & \\
\hline 20 & 19.70 & Mudstone & \\
\hline 19 & 9.20 & Medium-grained sandstone & \\
\hline 18 & 0.23 & Mudstone & \\
\hline 17 & 1.50 & 4\# coal & \\
\hline 16 & 280 & Sandy mudstone & \\
\hline 15 & 4.20 & 5\# coal & \\
\hline 14 & 0.03 & Sandy mudstone & \\
\hline 13 & 4.06 & Siltstone & \\
\hline 12 & 6.36 & Fine sandstone & \\
\hline 11 & 1.20 & Quartz sandstone & \\
\hline 10 & 230 & Limestone & \\
\hline 9 & 1.20 & 9\# coal & \\
\hline 8 & 0.70 & Limestone & \\
\hline 7 & 4.95 & Quartz sandstone & \\
\hline 6 & 0.40 & 10\# coal & \\
\hline 5 & 0.75 & Mudstone & \\
\hline 4 & 1.70 & $11 \#$ coal & \\
\hline 3 & 0.70 & Siltstone & \\
\hline 2 & 0.70 & Bauxite mudstone & \\
\hline 1 & 7.90 & Limestone & \\
\hline
\end{tabular}

(c)

FIGURE 1: 1508 Working Face profile. (a) Working face layout. (b) 1508 Working Face. (c) Comprehensive histogram of a coal seam in 1508 Working Face.

working face; $P_{1}$ is the support protection belt resistance; $P_{2}$ is the support resistance; $R_{x}$ and $R_{y}$ are the frictional resistance and support reaction force of the broken coal by the lower coal; $R$ is the support reaction force of the unbroken coal. $d s$ is the unit area of the linear sliding-type surface; $\alpha$ is the angle between the sliding surface of the blade and the coal wall; $\beta$ is the angle between the top beam of the support and the roof. $N$ is the axial concentration force of the slidingtype surface; $S$ is the tangential concentration force of the sliding surface. 


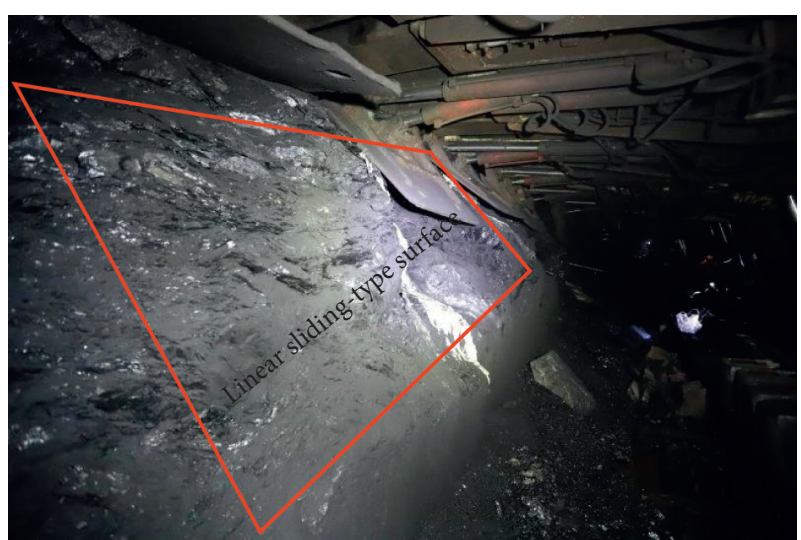

(a)

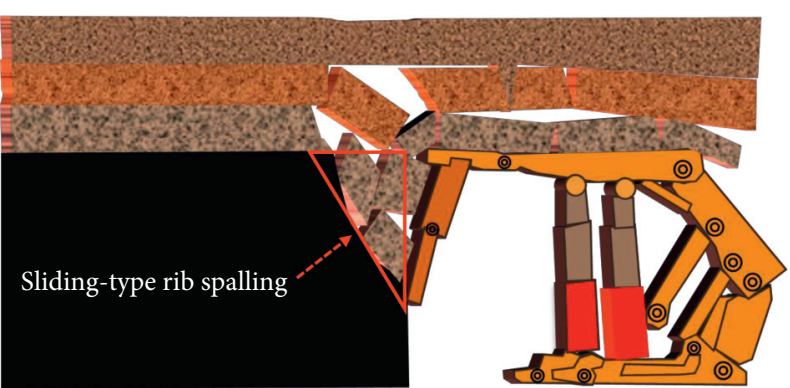

(b)

FIgURE 2: Rip spalling in 1508 Working Face. (a) Current status of rib spalling. (b) Sliding-type rib spalling.

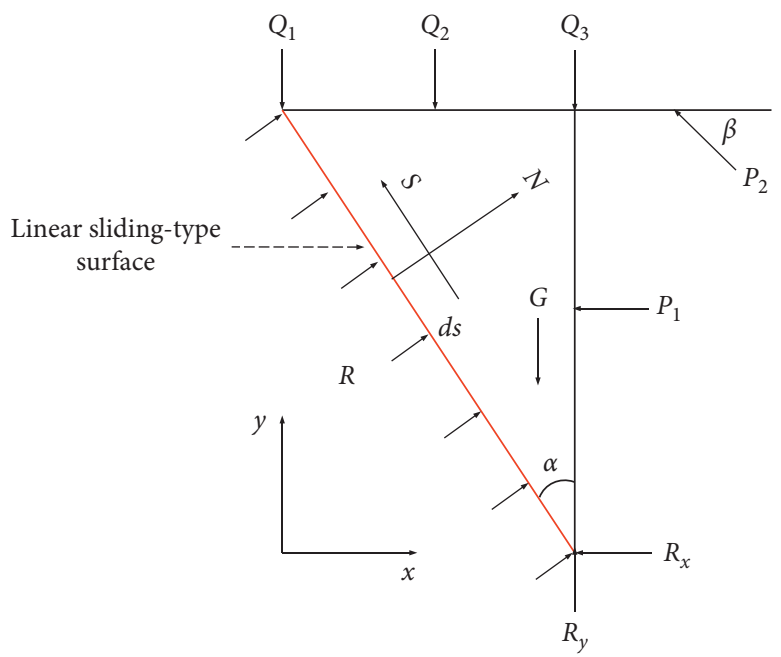

Figure 3: Mechanical model of sliding-type rib spalling.

According to the Mohr-Coulomb criterion, the angle $\alpha$ between the sliding-type surface of rib spalling and the coal wall is as follows:

$$
\alpha=\frac{\pi}{4}-\frac{\varphi}{2}
$$

$$
\begin{aligned}
& N=\int R d s+\left(P_{1}+R_{x}+P_{2} \sin \beta\right) \sin \alpha-\left(Q_{1}+Q_{2}+Q_{3}+G-R_{y}-P_{2} \cos \beta\right) \cos \alpha, \\
& S=\left(P_{1}+R_{x}+P_{2} \sin \beta\right) \cos \alpha-\left(Q_{1}+Q_{2}+Q_{3}+G-R_{y}-P_{2} \cos \beta\right) \sin \alpha .
\end{aligned}
$$

Then, the critical condition for rib spalling of the threesoft coal seam is as follows:

$$
K=N-\mu S \leq 0
$$

where $\mu$ is the friction coefficient of coal.

Based on the above analysis, the main influencing factors of rib spalling in the three-soft coal seam are the load of the coal, roof and the overlying rock, internal friction angle of coal, the cohesion, the support effect of the support, the shear strength of the coal, and the rotation angle of the main roof.

3.2. Mechanism of Grouting. Grouting reinforcement refers to the use of grouting pumps and other means to inject materials with strong permeability into the broken rock 
mass according to a certain pressure. The following explains the mechanism of grouting reinforcement from three aspects.

3.2.1. Improve the Strength and Rigidity of the Coal Wall Structure Plane. When the structural plane in the coal is relatively developed, its strength and stiffness are mainly controlled by the structural plane. When the strength and rigidity of the structural plane are low, it is relatively easy to separate, sliding or open along the weak structural plane, which leads to a decrease in the strength of the coal and an increase in its volume, thereby causing the rib spalling. After the reinforcement material is injected, the cracks in the structural plane are filled by the grouting material, which increases the cohesion and friction factor of the cracks, and thus the strength and rigidity of the coal wall are improved. It greatly reduces the probability of damage to the surrounding rock and coal wall along the weak structural plane, thereby increasing the overall strength of the coal wall of the working face and improving its physical and mechanical properties and self-bearing load capacity.

3.2.2. Enriched and Compacted Coal Cracks. When the grouting materials are injected into the coal wall, following the flow characteristics of the liquid, cracks inside the coal wall are filled, thereby reducing the porosity in the coal wall and reducing or disappearing the stress concentration of the cracks. The coal mass around the cracks is transformed from a two-dimensional stress state to a three-dimensional stress state, which significantly improves the stress distribution around the cracks, transforms the mechanical failure mechanism of the broken coal and rock mass.

Figure 4 is a comparison diagram of the mechanical properties of coal before and after grouting reinforcement. It can be seen from the figure that after grouting, the physical and mechanical characteristics of coal, such as coal compressive strength, cohesion, and internal friction angle, increase significantly, which leads to a reduction in the amount of rib spalling.

3.2.3. Transform Coal Failure Mechanism. According to the theory of fracture mechanics, when there are cracks in the coal body, the maximum stress concentration will appear at the ends of the cracks, and the stress concentration factor I:

$$
I=f\left(\frac{C}{W}, \frac{C}{\rho}\right)
$$

where $C$ is crack length; $\rho$ is the radius of the crack end; and $W$ is the ratio of the two to the rock mass size.

Therefore, the coal failure is the result of crack instability and expansion. After the cracks in the coal are filled with grouting materials, coupled with the binding effect of the grouting materials, that will greatly weaken the stress concentration at the ends of the cracks and then transform the failure mechanism of the coal and rock mass. Besides, when the coal wall is broken, the normal stress of the crack plane is 0 , and when the crack is filled with grouting

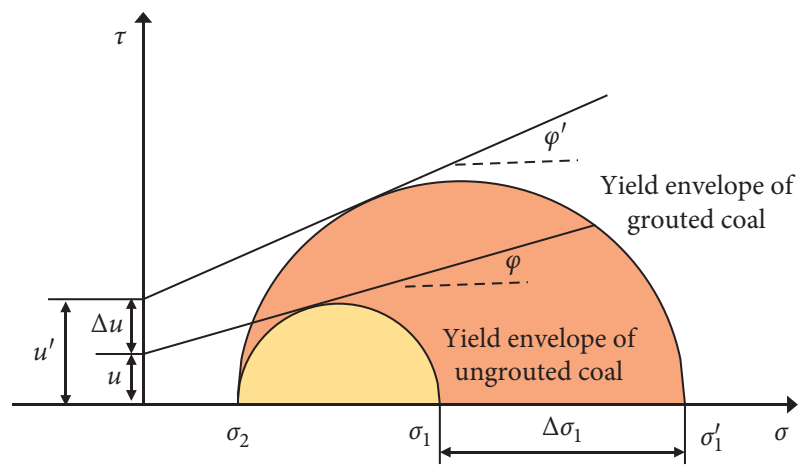

FIgURE 4: Comparison of mechanical properties of coal before and after grouting.

materials, it becomes a three-dimensional stress state. The expression of the principal stress of the Coulomb criterion is as follows:

$$
\sigma_{1}=\sigma_{3} \tan 2 \theta+R_{c},
$$

where $\sigma_{1}$ is the principal stress in the limit state; $\sigma_{3}$ is the third principal stress in the limit state, MPa; $\theta$ is the angle between the fracture surface and the largest principal plane; and $R_{c}$ is uniaxial compression strength.

Comprehensive analysis shows that, on the one hand, grouting reinforcement can enrich the cracks in the coal body and improve the strength and rigidity of the coal wall; on the other hand, it can reduce the stress concentration of the cracks and change the coal body failure mechanism. Thereby, it can prevent and control the disaster of rib spalling.

\section{Similarity Simulation Experiment}

It can be seen from Section 3.1 that the rib spalling of the three-soft coal seam is mainly closely related to the roof load. Therefore, a similar simulation experiment for the mining of the three-soft coal seam is carried out to grasp the characteristics of the roof load change.

4.1. Text Design. Taking the 1508 Working Face of Heyang Coal Mine as the engineering background, a similar simulation experiment of three-soft coal seam grouting was set up. The experiment was adopted a plane strain model frame with an external dimension (length $\times$ width $\times$ height $)=$ $3 \times 0.2 \times 1.6 \mathrm{~m}$. According to the similarity theorem, the geometric similarity ratio is $1: 250$. During the work process, the model is comprehensively monitored by the support pressure sensor, as shown in Figure 5.

4.2. Analysis of Roof Stress. According to the mining plan, an open cut $(2 \mathrm{~cm})$ was made at a $20 \mathrm{~cm}$ distance from the left boundary of the model, the support pressure sensor was installed, and the support pressure was increased to the support simulation setting force $(4.73 \mathrm{~kg})$. The mining distance was $1 \mathrm{~cm}$ each time, and the mining ends until the model 5\# coal seam was $20 \mathrm{~cm}$ away from the right 


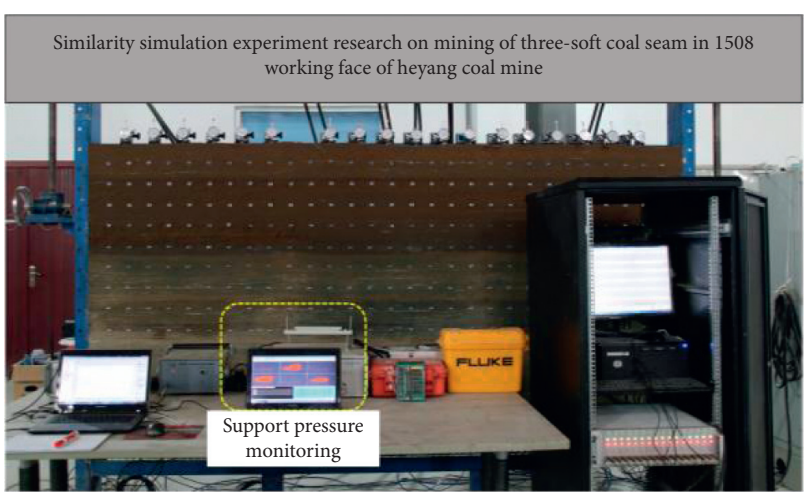

(a)

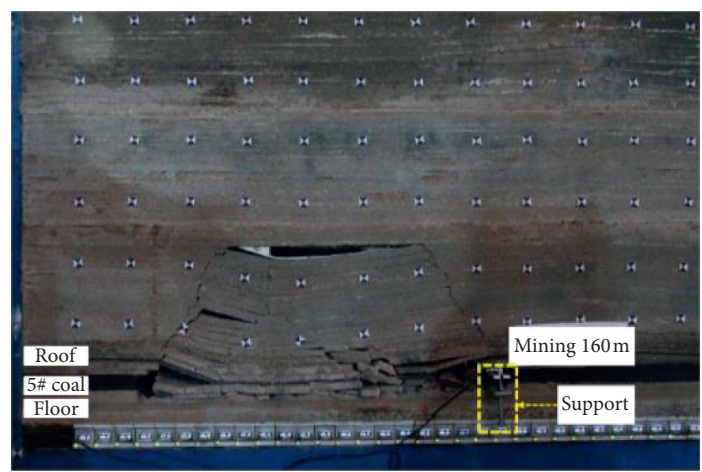

(b)

Figure 5: Similar simulation experiment of three-soft coal seam mining. (a) Overall real shot map. (b) Local real shot map.

boundary. A total of $260 \mathrm{~cm}$ was mined. When the model was fully mined, the stress distribution characteristics of the roof excavated to $447.5 \mathrm{~m}, 500.0 \mathrm{~m}, 525.0 \mathrm{~m}, 547.5 \mathrm{~m}$, and $560 \mathrm{~m}$ were calculated, as shown in Figure 6. It can be seen from formula (4) that the main factors that affect rib spalling include the roof load. And the roof stress at different advancing distances exceeds $25 \mathrm{~kg}$, which is much larger than the initial support force of $4.75 \mathrm{~kg}$, which can easily cause rib spalling. Therefore, grouting reinforcement research is urgently needed.

\section{Grouting Pressure Seepage Simulation}

5.1. Grouting Seepage Simulation Model. The grouting fluid diffusion radius is closely related to the grouting pressure, and the grouting fluid diffusion radius is an important basis for judging the grouting effect, so it is very important to choose a reasonable grouting pressure. According to the grouting feedback of the engineering site, the grouting pressure of the working face ranges from 4 to $10 \mathrm{MPa}$, so FLAC 3D numerical simulation software was used to simulate four grouting pressures of $4 \mathrm{MPa}, 6 \mathrm{MPa}, 8 \mathrm{MPa}$, and $10 \mathrm{MPa}$. And the pore pressure distribution characteristics of grouting holes under different grouting pressures were analyzed to select a reasonable grouting pressure. The grouting model is shown in Figure 7.

5.2. Pore Pressure Distribution. As shown in Figure 8, the cloud diagram is used to show the pore pressure distribution characteristics of different grouting pressure schemes along the grouting hole direction after 1 hour of grouting. The radial pore pressure has the highest pressure in the center of the borehole. The pore pressure around the borehole is circular, and the greater the grouting pressure, the smaller the area of the stress circle formed by the radial pore pressure.

As shown in Figure 9, the pore pressure along the axial direction of the grouting hole is the largest at the center of the borehole. The farther away from the center of the borehole, the smaller the pressure, and it also decays continuously along the radius of the borehole. And the greater the grouting pressure, the smaller the range of the

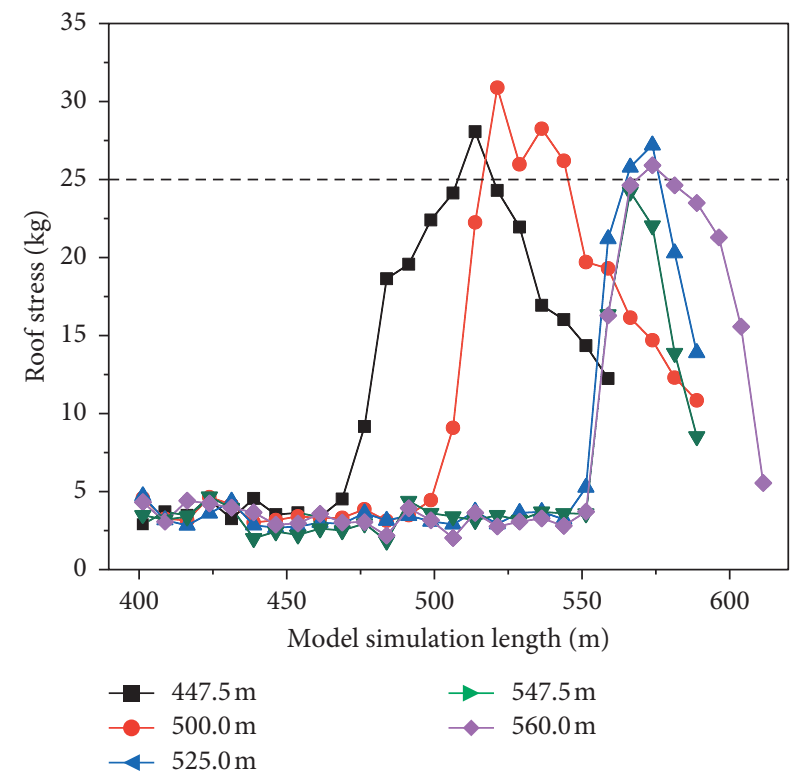

FIgURE 6: The stress characteristics of the roof at different advancing distances.

stress field formed by the axial pore pressure. According to the numerical simulation results, $10 \mathrm{MPa}$ is the best grouting pressure.

\section{Field Experiment}

6.1. Grouting Material. Silicate modified polymer grouting reinforcement material (SMPGM) is a new type of mining polymer grouting reinforcement material that has developed rapidly in recent years. Kang and Feng [26] pointed out that compared with traditional polyurethane grouting materials (PGM), through the study of silicate modification, the new materials not only retain the excellent mechanical properties of PGM themselves but also avoid the shortcomings of flammability and are suitable for grouting reinforcement of the surrounding rock of roadways. Table 1 shows the physical performance comparison between SMPGM selected in this experiment and traditional PGM. 


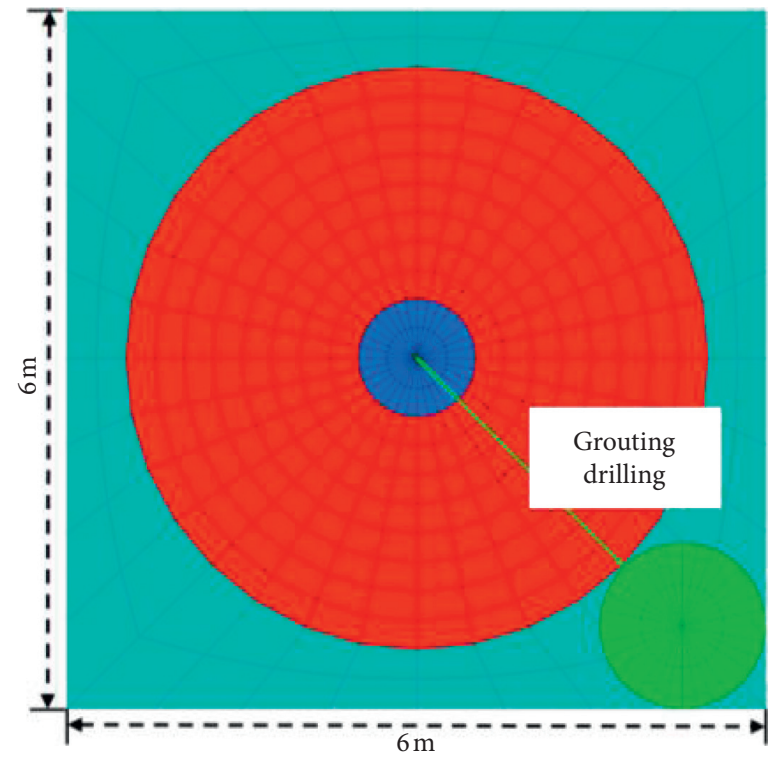

FiguRE 7: Grouting seepage simulation model.

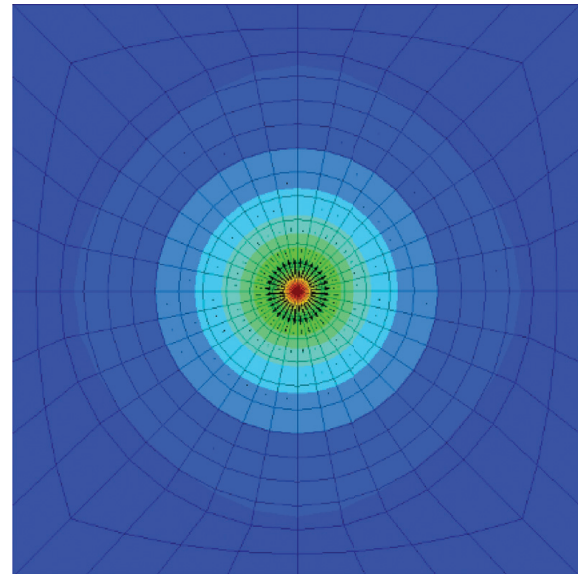

(a)

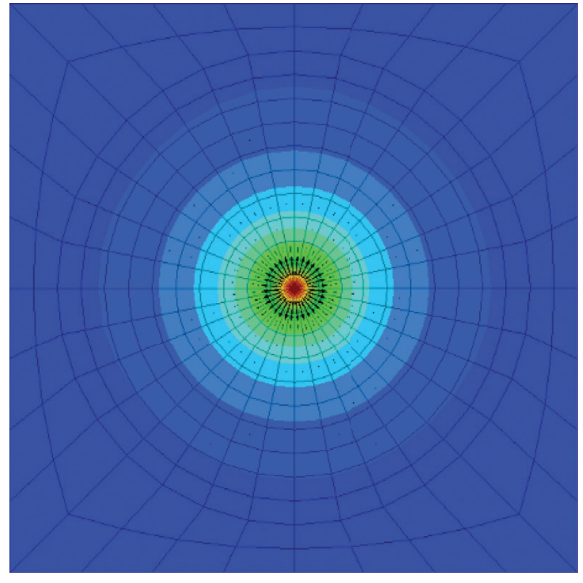

(c)

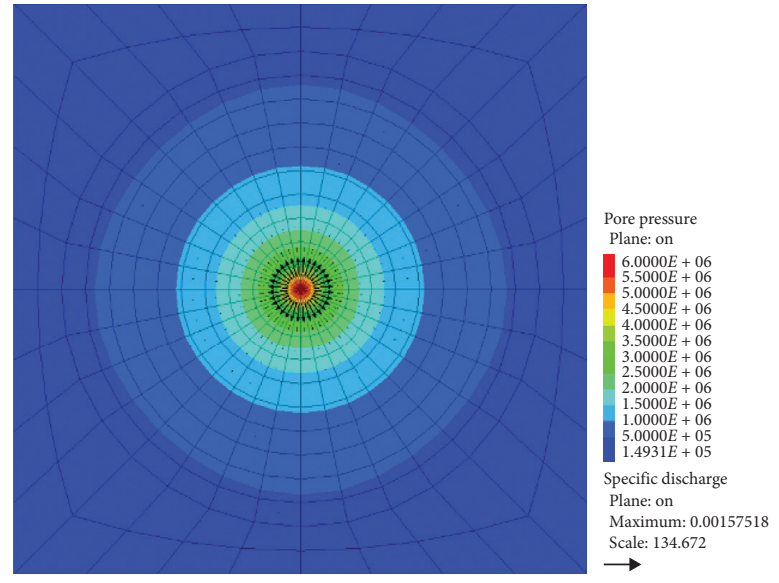

(b)

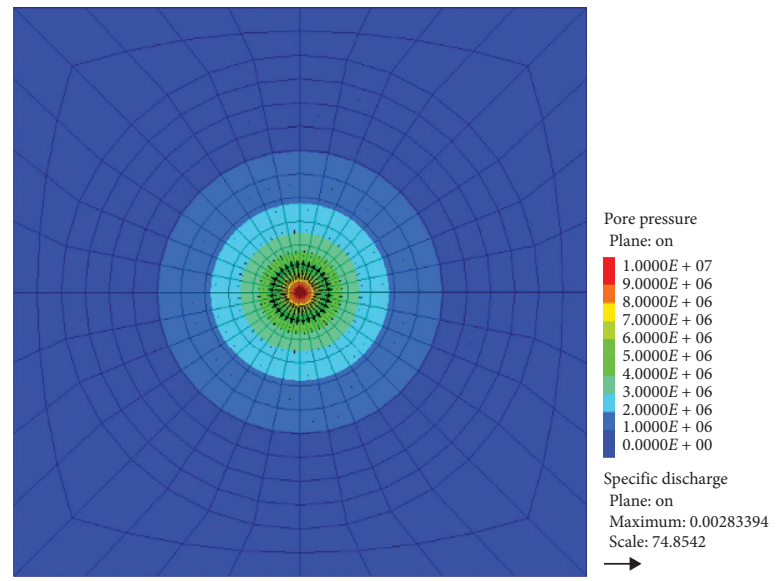

(d)

Figure 8: Distribution characteristics of radial pore pressure. (a) $4 \mathrm{MPa}$. (b) $6 \mathrm{MPa}$. (c) $8 \mathrm{MPa}$. (d) $10 \mathrm{MPa}$. 


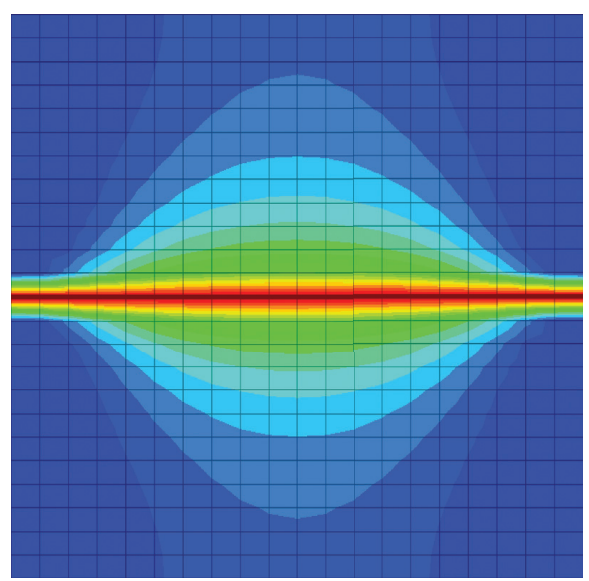

(a)

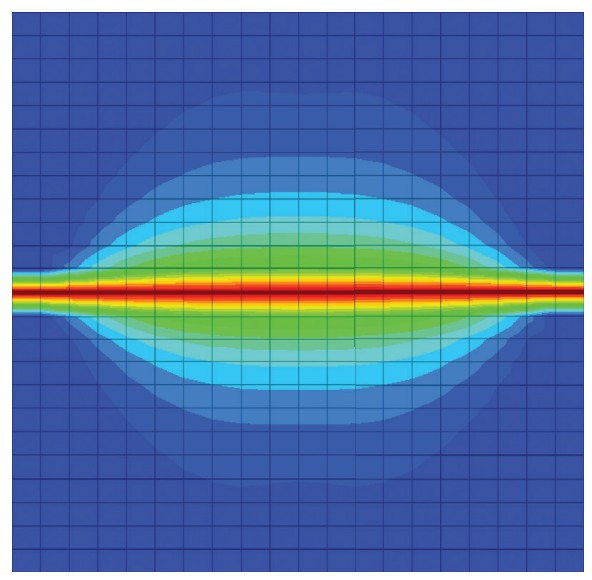

(c)

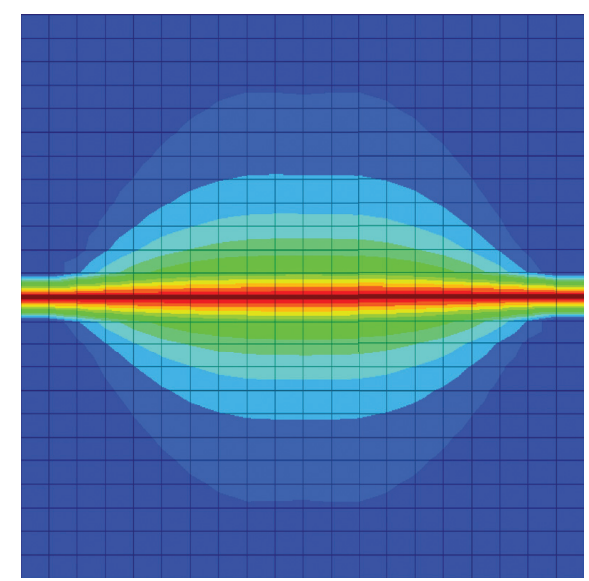

Contour of Gp pore pressure

$6.0000 E+06$

$5.5000 E+06$
$5.0000 E+06$

$5.0000 E+06$
$4.5000 E+06$

$4.0000 E+06$

$3.5000 E+06$

$3.0000 E+06$

$2.5000 E+06$

$2.0000 E+06$

$1.5000 E+06$

$1.0000 E+06$

$5.0000 E+05$

(b)

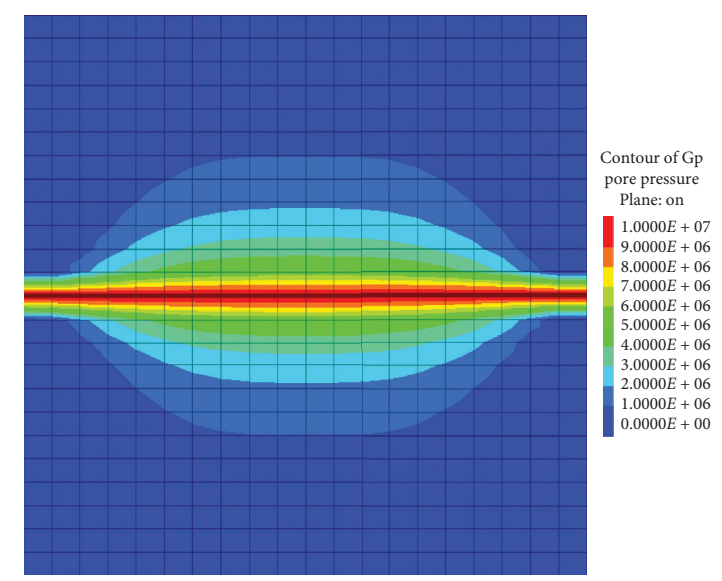

(d)

FIgURE 9: Distribution characteristics of axial pore pressure. (a) $4 \mathrm{MPa}$. (b) $6 \mathrm{MPa}$. (c) $8 \mathrm{MPa}$. (d) $10 \mathrm{MPa}$.

TABLE 1: Comparison of physical properties between SMPGM and traditional PGM.

\begin{tabular}{l}
\hline Physical and mechanical properties \\
\hline Viscosity after mixing/mPa.s \\
Complete consolidation time/s \\
Flash point $/{ }^{\circ} \mathrm{C}$ \\
Flame retardant properties \\
Reaction swelling \\
Maximum compressive strength/MPa \\
Maximum compression set $/ \%$ \\
Maximum shear strength/MPa \\
Maximum tensile strength $/ \mathrm{MPa}$ \\
Maximum bonding strength/MPa \\
Compression modulus/MPa \\
Viscosity after mixing $/(\mathrm{mPa} \cdot \mathrm{s})$ \\
Complete consolidation time $/ \mathrm{s}$ \\
Flash point $/{ }^{\circ} \mathrm{C}$ \\
Flame retardant properties \\
Reaction swelling
\end{tabular}

Reaction swelling

$\begin{array}{cc}\text { SMPGM } & \text { Traditional PGM } \\ 200 \sim 300 & 200 \sim 300 \\ 60 \sim 90 & 60 \sim 90 \\ >200 & >180\end{array}$

Fully flame retardant

$$
\begin{gathered}
1.0 \sim 1.1 \\
55 \sim 65 \\
20 \sim 25 \\
>20 \\
>20 \\
>4.0 \\
1400 \sim 1600 \\
200 \sim 300 \\
60 \sim 90 \\
>200
\end{gathered}
$$

Fully flame retardant $1.0 \sim 1.1$
Self-extinguishing from the fire

$$
\begin{gathered}
1.0 \sim 2.5 \\
60 \sim 80 \\
>30 \\
>20 \\
>20 \\
>4.0 \\
300 \sim 600 \\
200 \sim 300 \\
60 \sim 90 \\
>180
\end{gathered}
$$

Self-extinguishing from the fire $1.0 \sim 2.5$
In terms of flame retardant properties, SMPGM is completely flame retardant and does not need to add any harmful flame retardants, while traditional PGM is a flame retardant that is naturally free from fire and needs to be added with harmful elements such as chlorine, bromine, and phosphorus. Because the compressive elastic modulus of
SMPGM is higher than that of traditional PGM, the apparent mechanical performance is embodied as brittleness, which is conducive to the restoration of the overall structure of the broken coal and rock mass and the enhancement of the overall bearing capacity, which is more conducive to underground using. 
Besides, SMPGM also has the following characteristics: (1) Strong permeability and high bonding force; (2) High strength, excellent toughness, and it can adapt to surrounding rock; (3) It has strong applicability, and its reactivity and strength are not affected in any water environment; (4) The construction is quick and easy.

6.2. Scheme Design. Because of the current disaster situation in the 1508 Working Face, it was decided to carry out the grouting reinforcement experiment at the 25\# 35\# support. Between the 25\# 35\# supports, the boreholes are arranged $1.5 \mathrm{~m}$ below the roof, with an elevation angle of $20^{\circ}$ to make the bottom of the hole close to the roof of the coal seam to facilitate the reinforcement of the coal seam. The designed hole depth is $6 \mathrm{~m}$, and the hole diameter is $42 \mathrm{~mm}$.

Because the theoretical diffusion radius of SMPGM is $189.0 \mathrm{~cm}$, the diameter is $3.78 \mathrm{~m}$, the design hole spacing is $3 \mathrm{~m}$ to ensure the grouting effect. Grouting is carried out after the construction of one hole, and all the holes are filled in sequence. After every $4 \mathrm{~m}$ of the working face, drill again according to the above procedures to ensure the normal grouting and reinforcement work of the coal seam. The grouting hole layout design is shown in Figure 10.

According to the grouting design, the reinforcement area of each borehole is approximately $6 \mathrm{~m}$ in length, $3 \mathrm{~m}$ in width, and $3 \mathrm{~m}$ in height, and the volume of reinforcement is $6 \times 3 \times 3=54 \mathrm{~m}^{3}$. The porosity is calculated at about $2.2 \%$, as the grouting volume is $54 \times 2.2 \%=1.08 \mathrm{~m}^{3}$, the unilateral usage is $1.15 t$, and the usage of reinforcement material per drill hole is about $1.242 t$. The next round of grouting is carried out after every $4 \mathrm{~m}$ of advancement of the working face, which is carried out in a cycle. The required equipment and materials are shown in Table 2.

6.3. Experiment Process. The SMPGM is divided into A and $\mathrm{B}$ components. A two-liquid injection mixing gun was used to realize automatic mixing of $A, B$ components, which can achieve the dual purpose of mixing and uniform mixing through the mixing gun and be sucked out by the grouting pump and injected into the coal by a grout pipe. The diffusion radius of the grouting materials under normal fracture opening and porosity is $1.5 \sim 2.5 \mathrm{~m}$. When a large amount of grout seeps from the borehole, it means that the grout has filled the surrounding coal, the grouting was stopped. The two grouting times and grouting positions are shown in Table 3. To ensure the grouting effect, the average grouting volume of a single borehole is $1.32 t$. Figure 11 is a schematic diagram of grouting for coal wall in 1508 Working Face.

\subsection{Evaluation of Grouting Effect}

6.4.1. Analysis of Coal Wall Stability. In order to understand the actual grouting reinforcement effect and reinforcement radius, a series of observation holes were drilled around the grouting hole, and the YSZ(B) optical borehole sight was used to detect the borehole to fully understand the slurry penetration information. As shown in Figure 12, in the observation hole $4.5 \mathrm{~m}$ away from the grouting borehole, there is a clear white grouting material solidified and hardened body, and the reinforcing material at the hole wall is circled by a red coil. Since the coal body at the free surface of the coal wall is relatively soft, the image of the reinforcement effect at a distance from the orifice is more obvious. The hardened white reinforcement material can always be seen in the entire observation hole. It can be seen that the slurry has a better penetration effect in the coal body, and the grouting influence radius is at least $4.5 \mathrm{~m}$.

Figure 13 shows the coal wall during the advancement process of the working face before and after grouting reinforcement. It can be seen from Figure 13(a) that the surface of the coal wall was rough before grouting reinforcement, and the coal was severely damaged, causing the remaining coal to accumulate under the support. It can be seen from Figure 13(b) that the coal wall after reinforcement can see the seepage pattern of SMPGM in the coal during the mining process, that is, along the various cracks inside the coal and the microvoids in the bedding. The flow path not only directly proves the bonding effect of the slurry but also highlights the development of internal cracks in the coal. It can be seen from Figure 13(c) that the reinforced coal wall changed from the original soft and was extremely easy to rib spalling to a flat and straight coal wall during the mining process, and the reinforcement effect was good.

6.4.2. Analysis of the Amount of Rib Spalling. On September 6th, 2019, the first grouting reinforcement was carried out on the coal wall of the 1508 Working Face. The location of this grouting reinforcement was at the $25 \#, 27 \#, 29 \#, 31 \#, 33 \#$ for five supports. Figure 14(a) shows the amount of rib spalling before and after the first grouting. The average rib spalling before grouting is $0.47 \mathrm{~m}$ at the working face. Since the grouting started on September 6th, as the working face advanced, the average rib spalling will be reduced to $0.20 \mathrm{~m}$ in the next 8 days, which is a decrease of $57.45 \%$. On September 9th, 2019, the second grouting reinforcement was carried out. The location of this grouting reinforcement was 34\#, 37\#, 40\# for three supports. Figure 14(b) shows the amount of rib spalling before and after the second grouting. It can be seen from the figure that the average amount of rib spalling before grouting at the working face is $0.64 \mathrm{~m}$.

Since the grouting started on September 9th, as the working face advanced, the average amount of rib spalling will be reduced to $0.33 \mathrm{~m}$ in the next 7 days, which is a decrease of $48.43 \%$. Compared with the first time, the amount of rib spalling has been reduced. On the one hand, the most serious area of rib spalling is located between the 25\# 35\# supports, and on the other hand, it is due to the second the number of grouting drilling and amount of grouting materials are relatively small.

6.4.3. Analysis of the Mining Height. The changes of the mining height before and after grouting at the 1508 


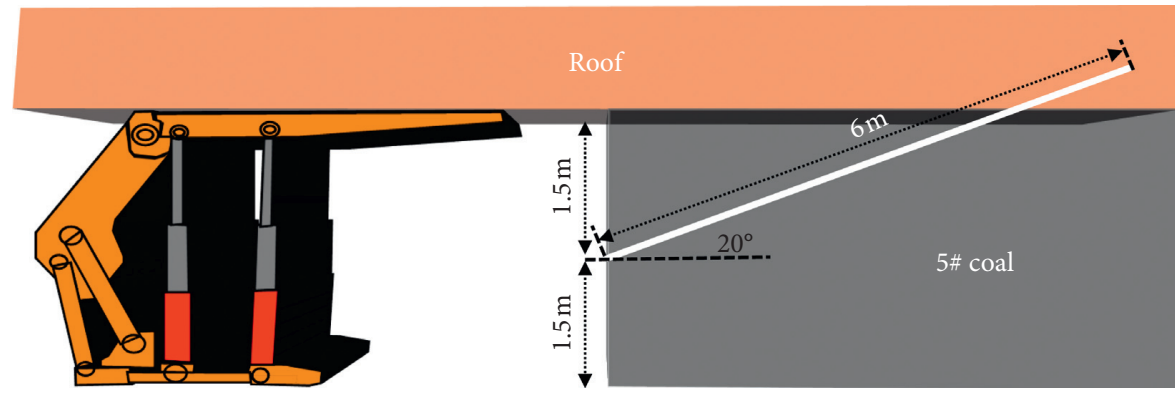

(a)

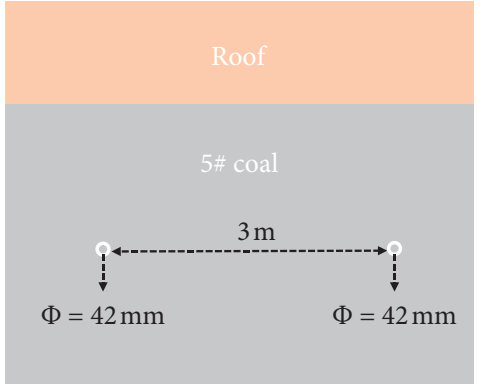

(b)

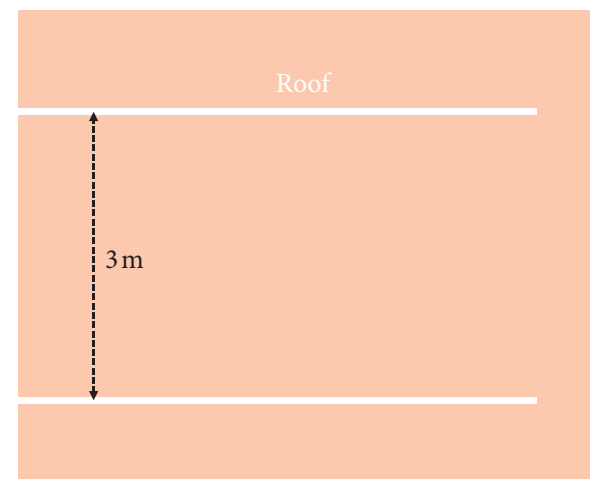

(c)

Figure 10: Grouting drilling design layout drawing. (a) Front view of drilling layout. (b) Side view of drilling arrangement. (c) Top view of drilling layout.

TABLE 2: Equipment and materials required for drilling construction.

\begin{tabular}{|c|c|c|c|}
\hline \multicolumn{2}{|r|}{ Equipment required for drilling } & \multicolumn{2}{|c|}{ Equipment and parameters required for grouting } \\
\hline Drilling rig & $\begin{array}{l}\text { ZQS-50/1.6S pneumatic handheld drill for } \\
\text { coal mine }\end{array}$ & $\begin{array}{l}\text { Pump and } \\
\text { parameters }\end{array}$ & Pneumatic special multifunctional grouting pump \\
\hline Drill pipe & $\Phi=38 \mathrm{~mm} * 1000 \mathrm{~mm}$ twist drill pipe & $\begin{array}{l}\text { Dynamic } \\
\text { parameters }\end{array}$ & $\begin{array}{c}\text { Mine air pressure } 0.4 \sim 0.7 \mathrm{MPa} \text {, air volume not less } \\
\text { than } 5 \mathrm{~m}^{3} / \mathrm{min}\end{array}$ \\
\hline Drill & $\Phi=42 \mathrm{~mm}$ & $\begin{array}{l}\text { Other spare } \\
\text { parts }\end{array}$ & $\begin{array}{c}\text { Extension pipe, blocker, flexible grouting pipe, mixing } \\
\text { gun, high pressure feeding pipe }\end{array}$ \\
\hline $\begin{array}{l}\text { Connect the } \\
\text { pipeline }\end{array}$ & $\begin{array}{c}\Phi=19 \mathrm{~mm} \text { high pressure connecting pipe; } \\
\Phi=19 \mathrm{~mm} \text { sealing ring }\end{array}$ & & \\
\hline
\end{tabular}

TABLE 3: Two grouting time and position of working face.

\begin{tabular}{lcccccccccc}
\hline Grouting time & \multicolumn{4}{c}{$2019-09-06$} & \multicolumn{2}{c}{ Total } & \multicolumn{2}{c}{$2019-09-09$} & Total \\
\hline Grouting position/\# support & $25 \#$ & $29 \#$ & $31 \#$ & $33 \#$ & $35 \#$ & 5 holes & $34 \#$ & $37 \#$ & $40 \#$ & 3 holes \\
Grouting volume/barrel & 46 & 28 & 40 & 40 & 30 & Totaling 5.1 tons & 60 & 30 & 60 & Totaling 4.2 tons \\
\hline
\end{tabular}

Working Face were counted and are plotted in Figure 15. From Figure 15(a), it can be seen that before the first grouting, the mining height was reduced due to the severe rib spalling, and the resource recovery rate was low. The average mining height of the working face was $2.72 \mathrm{~m}$, and the average mining height after grouting was $2.87 \mathrm{~m}$. Figure 15(b) shows that the average mining height of the working face before the second grouting was $2.62 \mathrm{~m}$, and the average mining height after the grouting was $2.85 \mathrm{~m}$. Comprehensive analysis shows that the mining height of the working face was increased significantly after grouting reinforcement. Due to the increase in the strength and cohesion of the working face coal wall, the amount of rib spalling was reduced, the roof fall was effectively improved, and the coal mining height was increased, which caused a reduction in resource waste. 


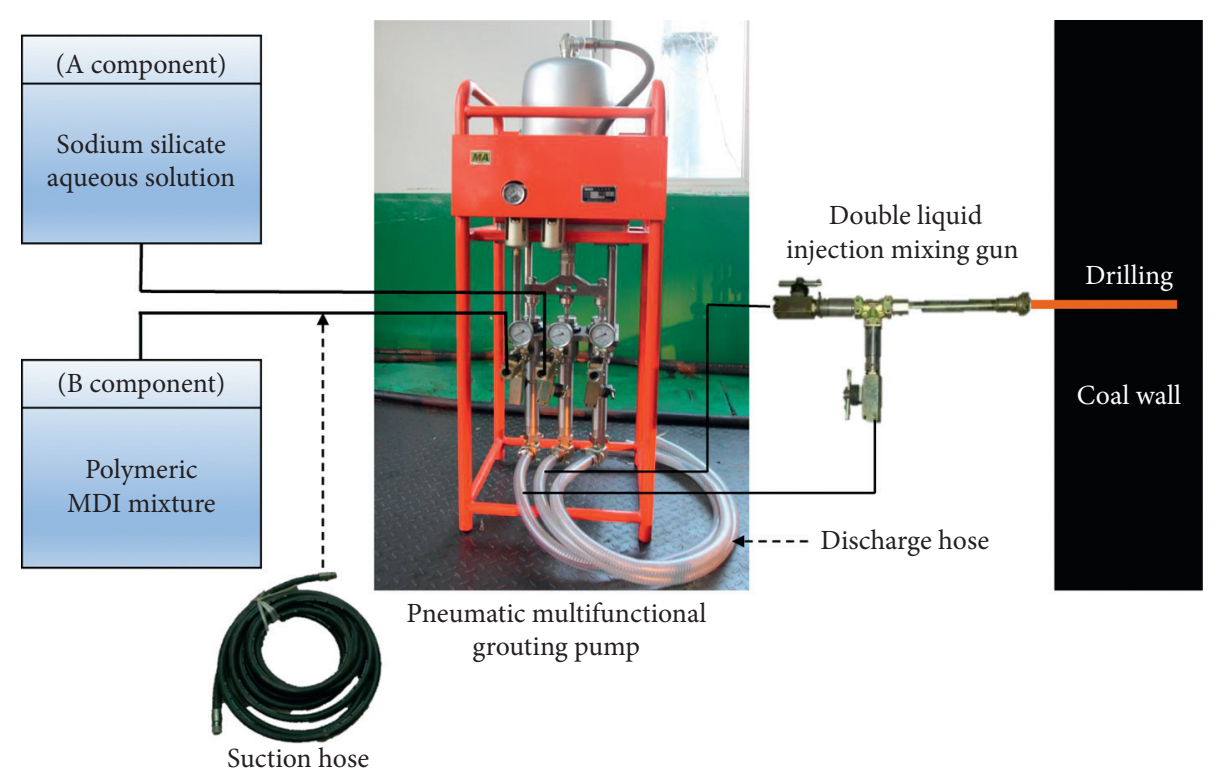

(a)

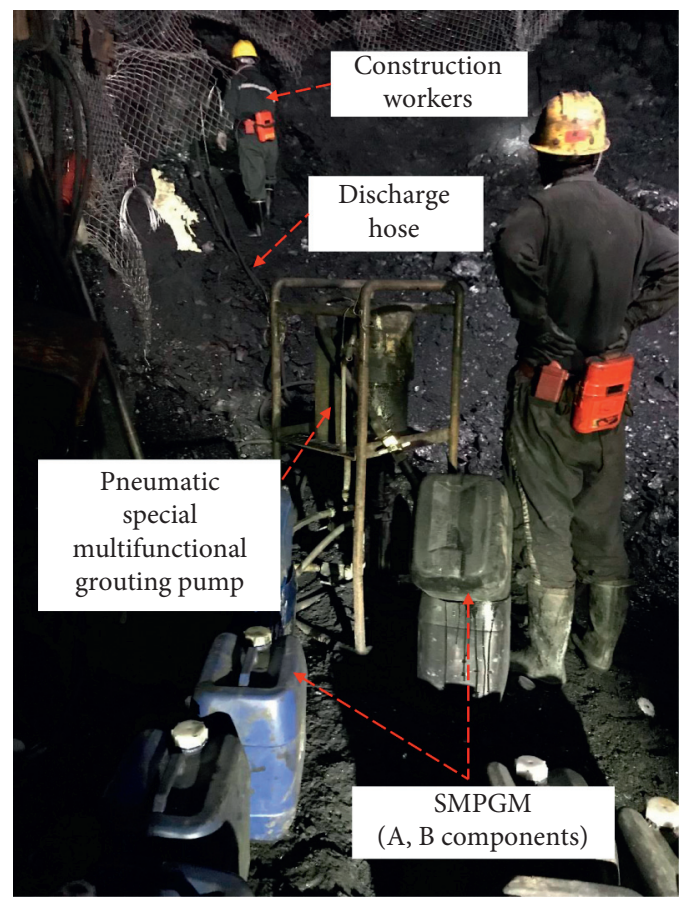

(b)

Figure 11: Continued. 


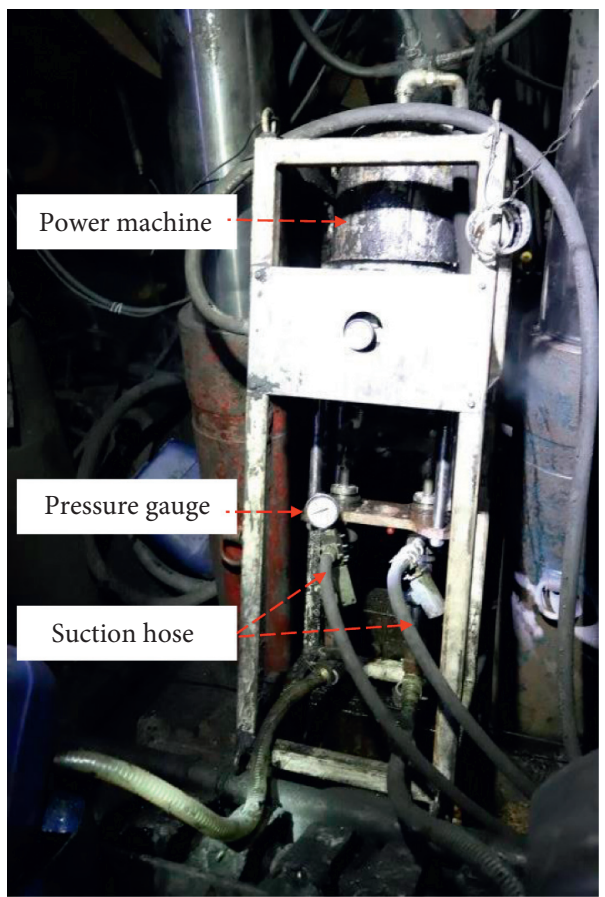

(c)

Figure 11: 1508 Working Face site construction. (a) Process diagram. (b) Site construction. (c) Multifunctional grouting pump.

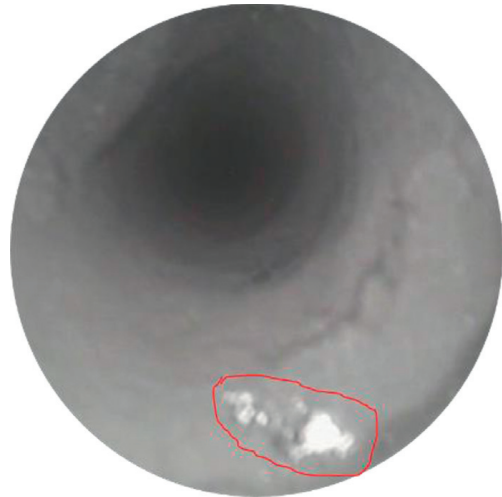

(a)

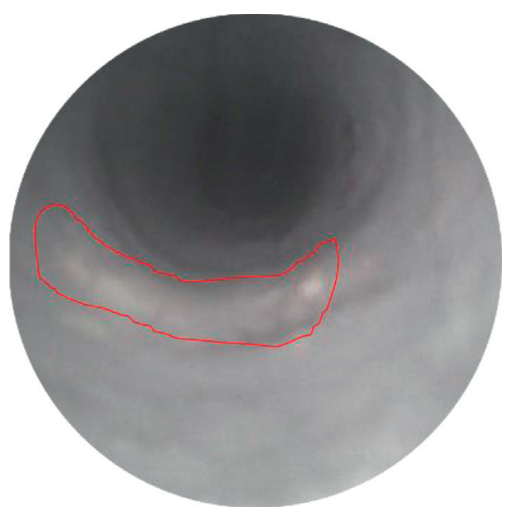

(d)

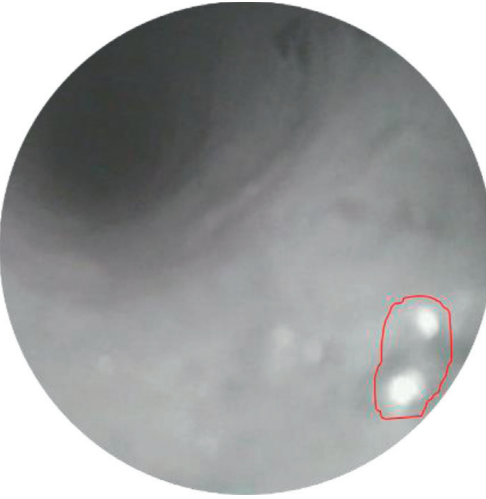

(b)

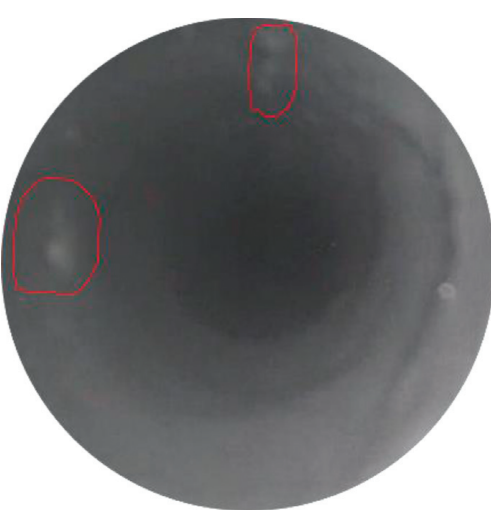

(e)

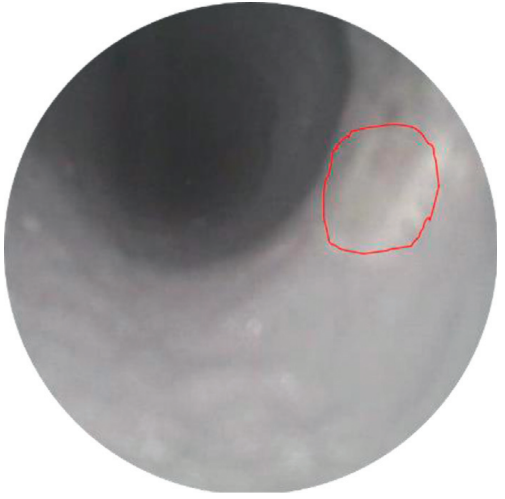

(c)

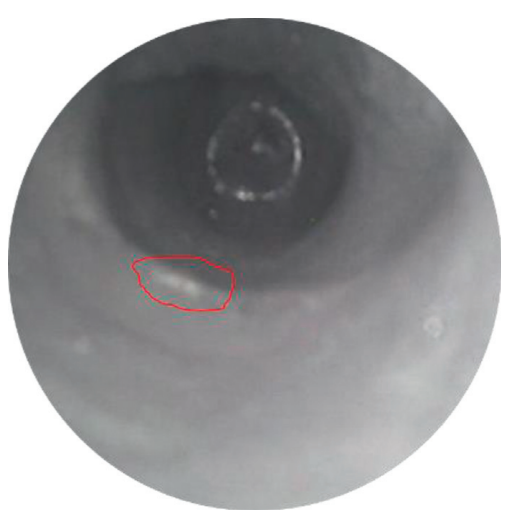

(f)

Figure 12: Drilling peeping characteristics of different hole depths. (a) $0.1 \mathrm{~m}$. (b) $0.5 \mathrm{~m}$. (c) $1.0 \mathrm{~m}$. (d) $1.5 \mathrm{~m}$. (e) $3.0 \mathrm{~m}$. (f) $4.5 \mathrm{~m}$. 


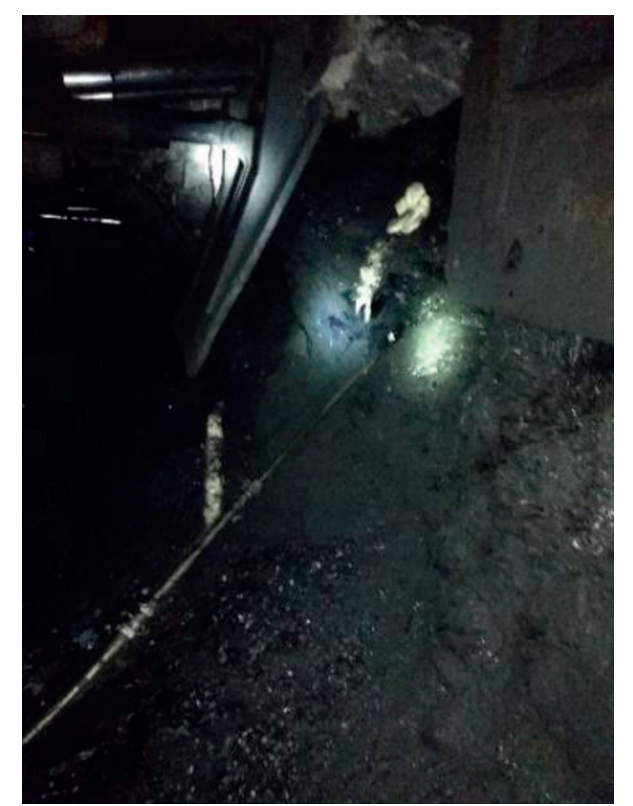

(a)

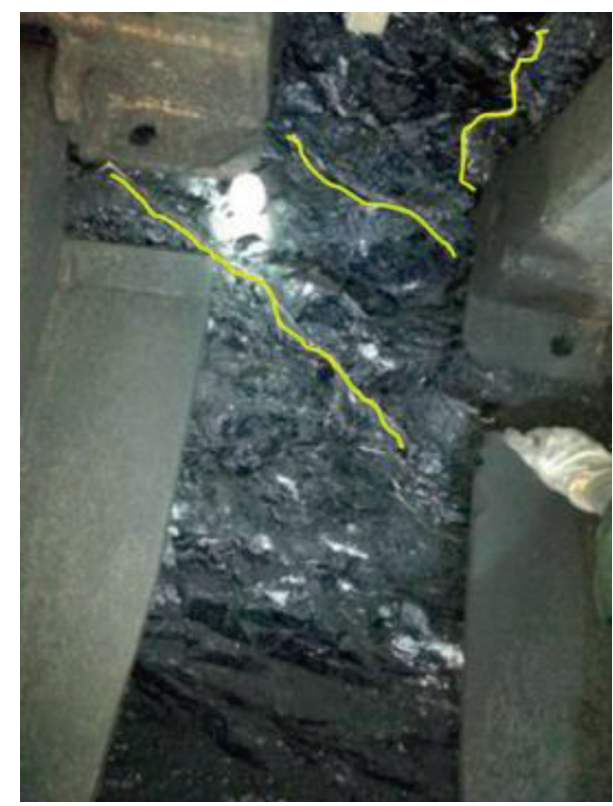

(b)

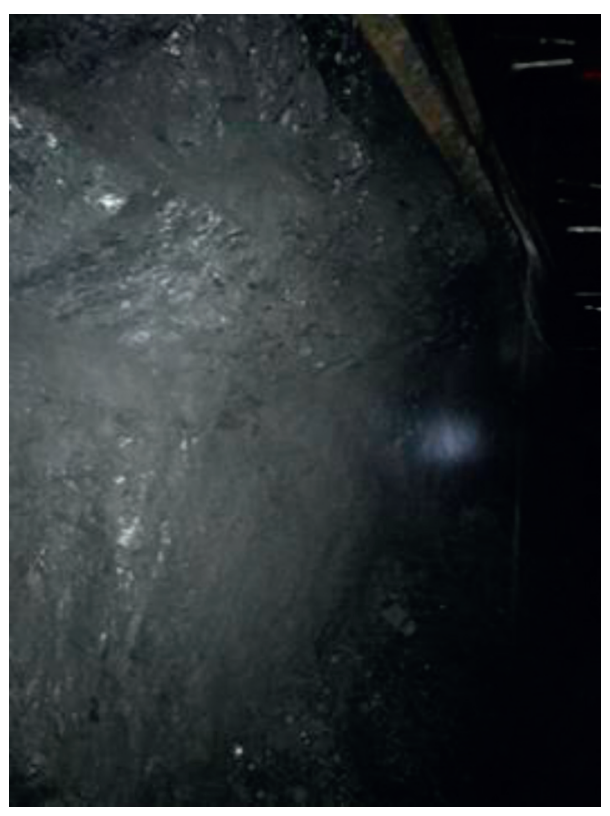

(c)

FIGURE 13: Stability of coal wall before and after grouting. (a) Broken coal wall before grouting. (b) Grout seepage lines. (c) Smooth coal wall after grouting reinforcement. 


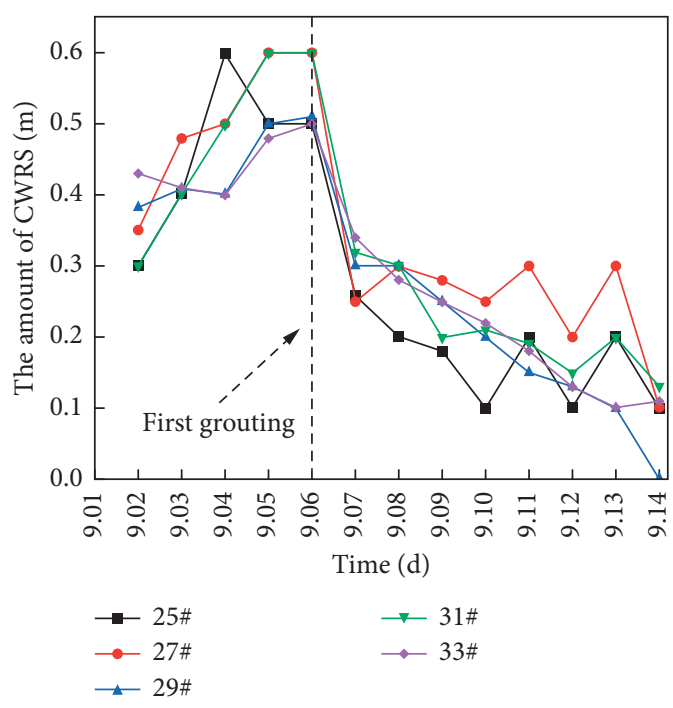

(a)

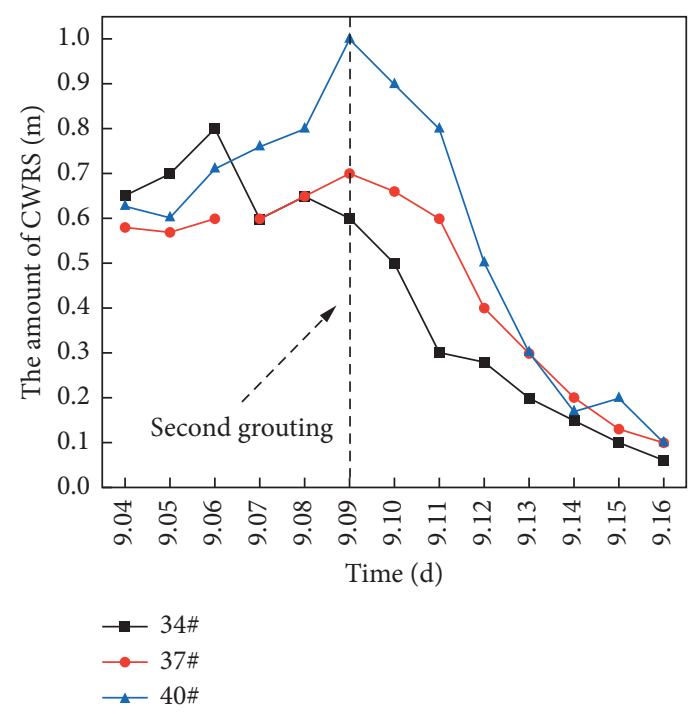

(b)

FIGURE 14: The amount of rib spalling before and after two groutings. (a) First grouting. (b) Second grouting.

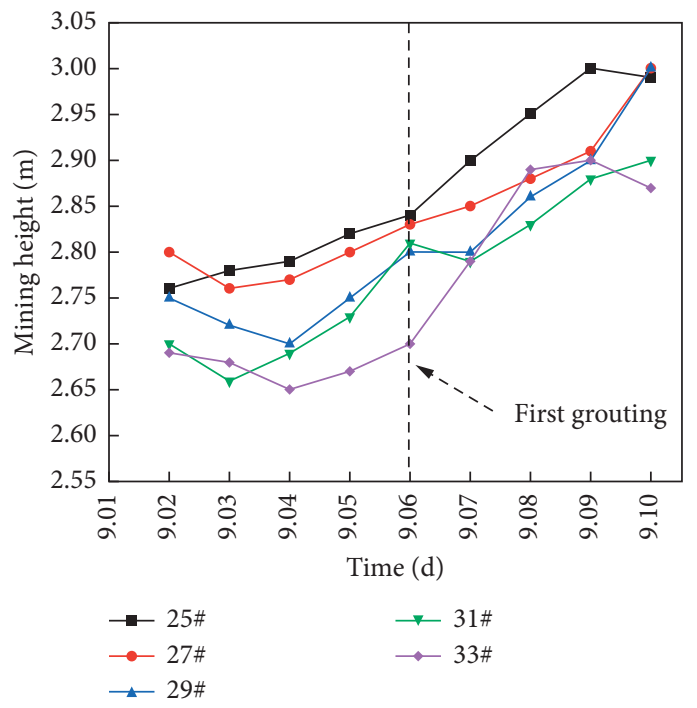

(a)

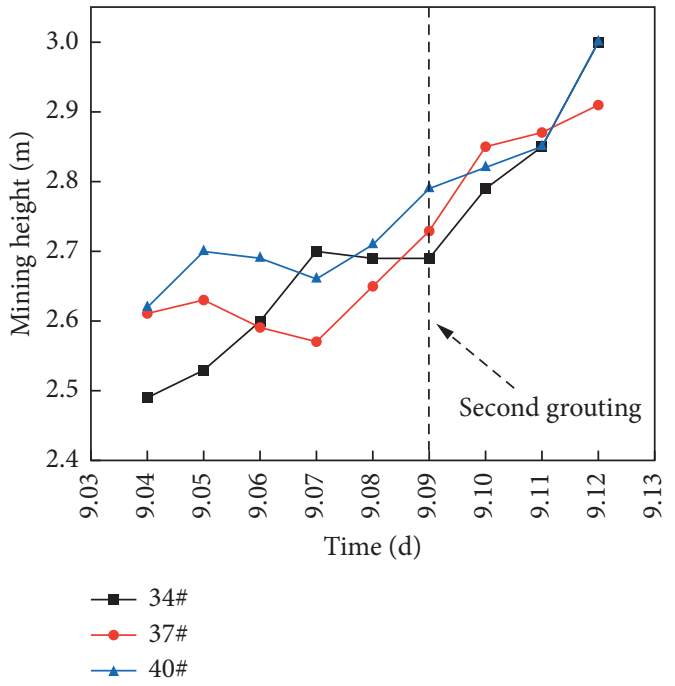

(b)

Figure 15: The mining height before and after two grouting: (a) First grouting. (b) Second grouting.

\section{Conclusions}

(1) By analyzing the status of rib spalling in the 1508 Working Face of Heyang Coal Mine, it is concluded that rib spalling in the three-soft coal seam is mainly sliding-type. The mechanical model of sliding-type rib spalling was established, and the main factors affecting rib spalling were determined. And the mechanism of grouting reinforcement technology was analyzed to prevent and control rib spalling from three aspects.

(2) Through similar simulation experiments, the evolution law of roof load under three-soft coal seam mining conditions was obtained. A numerical simulation experiment was used to analyze the pore pressure distribution characteristics of grouting holes under different grouting pressures, and the optimal grouting pressure was determined to be $10 \mathrm{MPa}$.

(3) On-site grouting test was carried out, and SMPGM was injected into the broken coal wall. The stability of the coal wall, the amount of rib spalling, the mining height were analyzed before and after the two grouting sections of the 1508 Working Face, and the results showed that after grouting reinforcement, the coal wall became flat and straight, the amount of rib spalling was significantly reduced, and the mining height was increased. The disasters of coal rib spalling have been effectively controlled. 


\section{Data Availability}

The data used to support the findings of this study are available from the corresponding author upon request.

\section{Conflicts of Interest}

The authors declare that they have no conflicts of interest.

\section{Acknowledgments}

This study was sponsored by the National Natural Science Foundation of China (No. 51874231), which is part of the Shaanxi Innovation Capability Support Program (Program No. 2020KJXX-006), the Shaanxi Natural Science Fundamental Research Program Enterprise United Fund (2019JLZ-04), and New Star of Science and Technology in Shaanxi Province. "Special Support Program" of Shaanxi Province in 2017 and Shaanxi Innovation Team Program (No. 2018TD-038) are gratefully acknowledged. The authors wish to acknowledge the financial supports of the Outstanding Youth Science Fund of Xi'an University of Science and Technology (2019YQ2-16).

\section{References}

[1] T. Kuang, Z. Li, W. Zhu et al., "The impact of key strata movement on ground pressure behaviour in the Datong coalfield," International Journal of Rock Mechanics and Mining Sciences, vol. 119, pp. 193-204, 2019.

[2] M. M. Sears, J. Rusnak, M. Van Dyke, G. Rashed, K. Mohamed, and M. Sloan, "Coal rib response during bench mining: a case study," International Journal of Mining Science and Technology, vol. 28, no. 1, pp. 107-113, 2018.

[3] S. K. Singh, H. Agrawal, and A. P. Singh, "Rib stability: a way forward for safe coal extraction in India," International Journal of Mining Science and Technology, vol. 27, no. 6, pp. 1087-1091, 2017.

[4] C. D. Martin and W. G. Maybee, "The strength of hard-rock pillars," International Journal of Rock Mechanics and Mining Sciences, vol. 37, no. 8, pp. 1239-1246, 2000.

[5] J. C. Wang, "Mechanism of the rib spalling and the controlling in the very soft coal seam," Journal of China Coal Society, vol. 32, no. 1, pp. 785-788, 2007.

[6] X. Q. Fang, J. He, and M. C. Li, "A study of the rib fall mechanism in soft coal and its control at a fully-mechanized top-coal caving face," Journal of China University of Mining \& Technology, vol. 38, no. 5, pp. 640-644, 2009.

[7] Y. H. Pang and G. F. Wang, "Hydraulic support protecting board analysis based on rid spalling "tensile cracking-sliding" mechanical model," Journal of China Coal Society, vol. 42, no. 8, pp. 1941-1950, 2017.

[8] S. L. Yang and D. Z. Kong, "Flexible reinforcement mechanism and its application in the control of spalling at large mining height coal face," Journal of China Coal Society, vol. 40, no. 6, pp. 1361-1367, 2015.

[9] H. Q. Han, W. Z. Jiang, and B. B. Guo, "Coal wall spalling mechanism and prevention technology of unstable seam with soft roof soft coal and soft floor," China Coal Science and Technology, vol. 44, no. 4, pp. 34-38, 2016.

[10] Y. Yuan, S. H. Tu, X. T. Ma, and L. L. Sun, "Coal wall stability of fully mechanized working face with great mining height in "three soft" coal seam and its control technology," Journal of
China Mining \& Safety Engineering, vol. 29, no. 1, pp. 21-25, 2012.

[11] D. W. Zhou, "Study on technology of soft coal seam rib spalling preventing by water infusion with shallow holes," 2009.

[12] Y. Heritage, "Mechanics of rib deformation-observations and monitoring in Australian coal mines," International Journal of Mining Science and Technology, vol. 29, no. 1, pp. 119-129, 2019.

[13] Y. G. Huang, "Seepage and diffusion mechanisms of boltgrouting slurry within fractured surrounding rocks on deep roadway," 2015.

[14] Y. P. Wu, D. Lang, and P. S. Xie, "Mechanism of disaster due to rib spalling at fully-mechanized top coal caving face in soft steeply dipping seam," Journal of China Coal Society, vol. 41, no. 8, pp. 1878-1884, 2016.

[15] H. Zhang and Y. P. Wu, "Coal wall caving mechanism of longwall large mining height stope in steeply dipping coal seams," Journal of China Mining and Safety Engineering, vol. 36, no. 2, pp. 331-337, 2019.

[16] S. F. Yin, "Rib spalling and control in fully- mechanized topcoal caving face with large mining height," 2015.

[17] H. J. Hao and Y. Zhang, "Stability analysis of coal wall in fullseam cutting workface with fully-mechanized in thick seam," Journal of China Liaoning Technical University, vol. 24, no. 4, pp. 489-491, 2005.

[18] G. Li, F. Ma, J. Guo, H. Zhao, and G. Liu, "Study on deformation failure mechanism and support technology of deep soft rock roadway," Engineering Geology, vol. 264, Article ID 105262, 2020.

[19] B. Yang, "Study on mechanism and control technology of rib spalling in fully mechanized caving face with great mining height of three-soft coal seam," 2012.

[20] J. C. Chang, G. X. Xie, and X. H. Zhang, "Analysis of rib spalling mechanism of fully-mechanized top-coal caving face with great mining height in extra-thick coal seam," China Rock and Soil Mechanics, vol. 36, no. 3, pp. 803-808, 2015.

[21] F. Cui, T. Zhang, X. Lai, and J. Cao, "Study on the evolution law of overburden breaking angle under repeated mining and the application of roof pressure relief," Energies, vol. 12, no. 23, Article ID 4513, 2019.

[22] Q. Wang, P. Rui, S. C. Li, and M. He, "Gob side entry failure mechanism and control of bolt-grouting in three soft coal seam," Journal of China Coal Society, vol. 41, no. 5, pp. 1111-1119, 2016.

[23] H. P. Kang and Z. Q. Feng, "Status and development tendency of roadway grunting reinforcement technology in coal mine," China Coal Mining Technology, vol. 18, no. 3, pp. 1-7, 2013.

[24] Z. Q. Feng, "Analysis and application of chemical grouting reinforcement mechanism to broken coal and rock mass," China Coal Science and Technology, vol. 10, pp. 32-38, 2008.

[25] H. G. Wu, D. Han, and H. Wu, "New research progress and application of the silicate modified grouting consolidation materials," China Coal Science and Technology, vol. 43, no. S1, pp. 29-31, 2015.

[26] H. P. Kang and X. C. Feng, "Status and development tendency of roadway grunting reinforcement technology in coal mine," China Coal Science and Technology, vol. 18, pp. 1-7, 2013. 